\title{
School Dropout Pattern among Senior Secondary Schools in Delta State, Nigeria
}

\author{
Ajaja, O. Patrick \\ Department Of Science Education, \\ Delta State University, Abraka, Nigeria \\ E-mail: osawaruajaja@yahoo.com
}

$\begin{array}{lr}\text { Received: July 15, } 2011 & \text { Accepted: August 3, } 2011 \quad \text { Published: April 1, } 2012 \\ \text { doi:10.5539/ies.v5n2p145 } & \text { URL: http://dx.doi.org/10.5539/ies.v5n2p145 }\end{array}$

\begin{abstract}
The major purpose of this study was to determine the pattern of dropout among secondary school students in Delta State. To guide this study, 7 research questions were asked and answered, 3 hypotheses stated and tested at 0.05 level of significance. The design of study was Expost facto using the past school attendance registers as the major instrument. The samples of the study consisted of 120 senior secondary schools and 120 vice principals. The collected data were expressed in percentages, and analyzed with t-test statistic. The major findings of this study included: (i) a higher percentage of dropouts in SSI, and a decline in SSII; (ii) a higher percentage of dropouts among females in all parameters; (iii) a higher percentage of dropouts in rural schools; (iv) a higher percentage of dropouts in mixed schools; (v) a higher percentage of dropouts in public schools; (vi) a significant difference on percentage dropouts between male and female single sex schools; (vii) a significant difference on percentage of dropouts between mixed and single sex schools; and (viii) a significant difference on percentage dropouts between schools in urban and rural areas. It was concluded that the single most important factor, which influenced pattern of dropouts, was student's sex.
\end{abstract}

Keywords: Single, Sex, Mixed, Public, Private, Urban and rural

\section{Introduction}

\subsection{Background of the Study}

School dropout in its simplest meaning is the untimely withdrawal from school. These students who withdraw from school prematurely end up not obtaining any certificate of graduation. The issue of school dropout is a global problem confronting the education industry round the world. Researchers like; Mohsin, Aslam and Bashir (2004); De Cos (2005); Bridgeland, Dilulio, and Morison (2006), and Oghuvbu (2008) have since buttressed this fact.

The issue of school dropout in Nigeria has been with us for a very long time. Fafunwa (1983) noted that dropout is one of the most serious problems that have continued to bedevil our educational system since independence in 1960 from the colonial administration. Even before our independence, the problem of dropout has already established its grip on our educational system. This can be buttressed with the remark made by Nuffied foundations in 1953 that in the West coast of Africa, a considerable proportion of student's dropout of school each year.

This study has come at a time when there is high rate of insecurity in the country as a result of criminal activities. Survey by both the print and electronic media tends to indicate that over $85 \%$ of the criminal activities perpetuated in Nigeria are done by youths who dropped out of school. This development has become a cause of serious concern to all well meaning Nigerians. This tends to suggest that our educational system is in trouble and thus needs a very serious attention in refocusing it and restructuring it for the attainment of national goals.

De Cos (2005) commenting on the importance of graduation from high school noted that; with the economy changing from a dependence on manufacturing towards more reliance on technology, services, and a "knowledge economy", the need for education beyond high school has grown. In Nigeria of today, Senior School Certificate is considered as the minimum required for most jobs and status positions. This development has serious implications for the economic well being of dropouts and the society at large. In this era of global economic meltdown and global economic competitiveness, Nigeria as a nation that has vision must make concerted efforts to raise the educational attainment of all its youths who are the leaders of tomorrow.

Globally, reasons why students dropout from school can be categorized into four clusters. These include; School 
related, Job related, family related, and community related. Study by Frendenberg and Ruglls (2007) identified twenty four factors under family cluster; three factors under community cluster and twelve factors under school cluster. The factors identified under family cluster include; low family socioeconomic status, racial or ethnic groups, male, special education status, low family support for education, low parental education, residential mobility, low social conformity, low acceptance of adult authority, high level of social isolation, disruptive behaviour conduct, being held back in school, poor academic achievement, academic problems in early grades, not liking school, feelings of "not fitting in" and of not belonging, perceptions of unfair or harsh disciplines, feeling unsafe in school, not engaged in school, being suspended or expelled, conflicts between work and school, having to work and school, having to work or support family, substance use and pregnancy. In community cluster, the following factors were indentified: living in a low income neighborhood, having peers with low educational aspirations and having friends or siblings who are dropouts. Under school related cluster, these factors were indentified; low socioeconomic status of school population, high level of racial or ethnic segregation of students, high proportion of students of colour in high school, high proportion of students enrolled in special education, location in central city, large school district, school safety and disciplinary policies, high-stakes testing, high student -to- teacher ratio, academic tracking, discrepancy between the racial or ethnic composition of students and faculty, and lack of programmes and support for transition into high for $9^{\text {th }}$ and $10^{\text {th }}$ graders. While job related cluster entails: those students who could not work and school at the same time, those who had to do a job to survive and those who found job.

It must be stressed at this point that variables in each of the clusters are not all conclusive. The reasons why students dropout of school vary from one society to another, and from one country to another. For example, in Pakistan, Mohsin et al (2004) found weak primary education system, non-availability of trained teachers, and parent-teacher relationship as the major causes of dropouts.

The studies by National center for Education Statistics (1998), Vermont Agency of Human Services (1999), De Cos (2005) and Bridgeland et al (2006) identified five major reasons why students dropout of school in U.S. These include; (i) classes not interesting, (ii) missed school for many days and could not cope again, (iii) spent a lot of time with those not interested in school, (iv) have absolute freedom to do what I like and (v) failing in school.

Most of the researches on the causes of dropout in Nigeria isolated the following: (i) Poor educational background of parents, (ii) inability of parents to pay their children school fees, (iii) failure in school examination, (iv) very poor state of facilities in schools, (v) unemployment of graduates, (vi) broken homes, (vii) types of parents occupation, (viii) school discipline policies, (ix) teenage pregnancy, (x) early marriage and (xi) very early ambition for self business and employment.

Literature on dropout isolated six predictive factors for dropping out of high school. These include: (a) grade retention (being held back to repeat a grade); (b) poor academic performance; (c) moves during high school; (d) high absenteeism; (e) misbehaviour, and (f) the students feeling that no adult in the school cares about his or her welfare. Students with the above characteristics have very high tendency to drop out of school.

The consequences of dropout for both students and the society are substantial and far reaching. The decision to dropout is a dangerous one for the student, particularly in this age of technologically controlled economy in which workers needs a lot of skills to compete in the workforce. Dropouts are much more likely than peers who graduated to be unemployed, living in poverty, receiving public assistance, in prison on death row, unhealthy, divorced and ultimately single parents with children who will dropout from high school themselves.

National center for education statistics (1998) identified three other secondary and indirect problems emanating from dropout. These include: (i) high school dropouts are more likely to receive public assistance than high school graduates who do not go on to college; (ii) this increased reliance on public assistance is likely due, at least in part to the fact that young women who dropout of school are more likely to have children at younger ages and more likely to be single parents than high school graduates; and (iii) the individual stresses and frustrations associated with dropping out have social implications as well; dropouts make up a disproportionate percentage of the nation's prisons and death row inmates.

Improving graduation rates is a specific objective that can bring educators together for research, intervention, and advocacy to improve the lives and well-being of young people (Freudenberg and Ruglls 2007). Although a comprehensive analysis of multidisciplinary studies on strategies to reduce the incidence of dropout is beyond the scope of this study, Bridgeland et al (2006) advocates on what might help students stay in school are highlighted below: (a) improve teaching and curricula to make school more relevant and engaging to enhance the connection between school and work; (b) improve instruction and access to support for struggling students; (c) ensure strong adult-student relationships within the school; (d) build a student relationships within the school; and (e) improve the communication between parents and school. 
From the foregoing, I have attempted to explain the meaning of school dropout, discussed the seriousness of the problem, x-rayed the causes and characteristics of possible dropouts, highlighted the consequences of dropout, and finally the strategies to reduce dropout. Instead of replicating studies that dealt on the above recurring variables, this study concentrated its efforts on dropout patterns in institution types and environments. The institution types of interest included; single sex, mixed, private and public schools, while the environments of interest are urban and rural areas. It is intended that the findings of this study will provide the necessary information that will enhance the quick implementation of recommended strategies that will reduce the incidence of dropout in our schools.

\subsection{Statement of the Problem}

This study was carried out to correct the imbalance in research efforts on our knowledge of school dropout. Most of the researches on dropout have been centered on causes, effects and remedies. Most if not all the researches in Nigeria on the same subject matter followed the same pattern. No studies to my knowledge in Nigeria studied dropout problems using the parameter "pattern of dropout" under the influences of school type and environment. This study is therefore very timely and significant. The statement of the problem therefore is, will the evaluation of dropout patterns among senior secondary schools in Delta State identify the most vulnerable groups susceptible to dropout from school?

\subsection{Research Questions}

To guide, direct and focus this study, the following research questions were raised:

1) What is the pattern of dropout of students in single and mixed senior secondary class one (SS1) and senior secondary class three (SS 111)?

2) What is the pattern of dropout of students in public and private schools between SS1 and SS111?

3) What is the pattern of dropout of students in urban and rural schools between SS1 and SS111?

4) Is there any difference in the percentage of dropout between single male and female schools?

5) Is there any difference in the percentage of dropout between mixed and single sex schools?

6) Is there any difference in the percentage of dropout between schools in urban and rural areas?

7) Is there any difference in the percentage of dropout between public and private schools?

\subsection{Research Hypotheses}

The following hypotheses were stated and tested at 0.05 level of significance.

$\mathrm{H}_{\mathrm{O} 1}$ : There is no significant difference in percentage dropout between male and female single sex schools.

$\mathrm{H}_{\mathrm{O} 2}$ : There is no significant difference in percentage dropout between mixed and single sex schools.

$\mathrm{H}_{\mathrm{O} 3}$ : There is no significant difference in percentage dropout between schools in urban and rural areas

\section{Methodology}

\subsection{Design of the Study}

The design employed for the study was expost facto. This entails the use of past records of subjects to arrive at conclusions about them. For this study, the school class attendance registers were used to determine the incidence of dropout and percentage of dropout among schools.

\subsection{Population and Sample of the Study}

The population of the study consisted of all senior secondary schools and their students (public and private) in Delta State of Nigeria. There are about 1240 public and government approved senior secondary schools in Delta State. Delta State is divided into three senatorial districts: Delta North, Delta Central, and Delta South. The three districts put together have 25 local government areas.

The sample of study consisted of 120 senior secondary schools randomly selected to reflect school types (single sex and mixed, private and public) and school environment (urban and rural). Of the 120 senior secondary schools, 30 of them were private schools ( 10 from each senatorial district), 90 public schools made of 60 mixed schools (20 from each district) and 30 single sex schools (10 from each district). A sample of 120 Vice Principals (VPs) was used as sources of data collected.

\section{Instrument}

One major instrument was used for data collection. The instrument was the school attendance register which included those for SSI, SSII and SSIII. The school attendance registers are school records kept by the Vice Principal 
Academics.

No form of validation was carried on the instrument. The reason was because the instrument is an original source of information. Any data collected from an original source is seen as correct and accurate and the instrument when used for data collection is adjudged as reliable (Wiseman, 1999; Johnson and Christensen, 2000; Borich, 2004).

\subsection{Procedure for Data Collection}

The data used for the study were collected by a team of four persons. These included 3 research assistants and the researcher. For the effective collection of data from the sampled schools, the 120 schools were shared among the researcher and the research assistants. Each person collected data from 30 senior secondary schools. Through the assistance of Vice Principal Academics of each sampled school, attendance registers of each class in each sampled school as they moved from SSI through SSIII were collected, analysed and incidence of dropout recorded. The duration for data collection was two weeks. Fridays were excluded from days of data collection because of school labour, and cleaning the school compound which most often takes place on Fridays.

\section{Result}

Generally, Table 1 indicates the following:

(i) Percentage of dropout was highest in SS1 using all the parameters stated.

(ii) Percentage of dropout declined during transition from SSII to SSIII using all parameters.

(iii) Percentage of dropout was highest in rural schools.

(iv) Percentage of dropout was least in private schools.

(v) Percentage of dropout among female students was higher than that of the males using all the stated parameters.

Specifically, Table I shows the following:

(i) On single sex schools, the percentage of dropout was highest in girl's schools than in boy's schools.

(ii) The percentage of dropout was higher in mixed schools when compared with single sex schools. The percentage of dropout was higher among the female students than among the male in mixed schools.

(iii) The percentage of dropout was higher in public schools than in private schools - both with male and female students. In the public schools, the percentage of dropout among female students was higher than among males.

(iv) In rural schools, the percentage of dropout was as high as $35.39 \%$. The female dropouts in rural schools were higher than males, $42.10 \%$ as against $28.67 \%$.

(v) The percentage of dropout in urban schools was lower when compared with rural schools, $22.92 \%$ as against $35.39 \%$. Percentage of dropout was still higher among female students in urban schools, $24.28 \%$ for females as against $21.47 \%$ for males.

Shown in Table 2, the mean percentage drop out of female students (23.29\%) is higher than that of the males (19.00). A significant difference was found in the percentage dropout between males and females in single sex schools, $(\mathrm{t}$ $=12.23, \mathrm{P}<0.05$ ), with this result, hypothesis 1 was rejected.

Table 3 , shows a significant difference in the percentage of dropout between student in mixed and single sex schools, ( $\mathrm{t} 10.13, \mathrm{P}<0.05$ ) with this result hypothesis 2 was rejected.

Shown in Table 4, a significant difference was found on percentage of dropout between urban and rural schools, $(\mathrm{t}=$ $27.68, \mathrm{P}<0.05)$. With this finding, hypothesis 3 was also rejected.

\section{Discussion}

The findings of this study are most significant in the sense that its area of focus broke away from the usual procedure for studying student's dropout from schools. The previous areas of emphases on dropout studies centered on causes, effects and remedies. These have made the comprehension of dropout problems incomplete. This study, which centered on pattern of dropout among secondary school student's has taken our knowledge of dropout to a higher level. The study has clearly demonstrated the pattern of dropout in various school types and school environments studied. The findings of this study therefore, have given clues on the appropriate time to act to reduce the incidence of dropouts.

The two most significant findings of this study as regard the patterns of dropout are: (i) that the incidence of dropout is highest, in SSI; and (ii) that the incidence of dropout declined in SSII. This tends to suggest that when students are promoted to SSII their attitude towards schooling is improved resulting in their willingness to remain. This may be 
the reason why the incidence of dropout of students declines after promotion to SSII. These findings therefore suggest that the appropriate time to act so that the incidence of dropout among students can be reduced significantly is when they are in SSI. It therefore follows that no effort should be spared in SSI to encourage and make students to remain in school.

On the relationship between sex and dropout from school, this study found that female students are the most vulnerable group that dropout of school. This may be true considering the variables of school type and school environment used in the study and the findings. Using all these parameters, the female students recorded the highest incidence of dropouts. This situation may have been created by issues of early marriage and teenage pregnancy most often associated with females. This position agrees with the findings of Kaufman, Denise \& Jeffery (1992), Swanson (2004) Greene and Marcus (2002) Balfanz, and Nettle (2004) and Greene and Marcus (2005). They all found that females dropout of school most.

On the relationship between school type and dropout considering private and public schools, the finding of this study indicates that the incidence of dropout is highest in public schools. Considering all the parameters used in this study (school type and school environment) the incidence of dropout was least in private schools. This may not be unconnected with the fact that both the teachers and school administrators in private schools are more alive to their responsibilities than those in public schools. The state of infrastructure in private schools are by far better than those in public schools. This may have encouraged both the students and their parents to have fate in schooling.

The significant difference found between the number of students who dropout from schools in single sex and mixed schools to the detriment of mixed schools is not surprising. Firstly, the incidence of dropout being highest among mixed schools may have been caused by some immoral relationships among students, which most often result in expulsion (e.g. teenage pregnancy, cultism, and other serious misbehaviours). Secondly, putting two groups who do not have the same abilities together create frustration and complex problems, which may result in dropout. If students of same sex are put together, they perform better than those mixed and the incidences of complexes are minimized. This agrees with the findings of Ajaja, Kpangban and Onwuegbu (2007). They found students in single sex schools to be better than those in mixed schools in science achievement tests.

On school environment, a significant difference was found in dropouts to the detriment of rural schools on comparison of schools located in urban and rural environments. This however, contradicts the finding of an earlier study carried out in South Eastern part of Nigeria. Okoye (1991) found a higher incidence of dropout in urban areas particularly among the males. He explained that the reason for that was because of the influence of the markets, which draw attendants in shops from the young males in the environment. This position agrees with the findings of Bridgeland et al (2006) and De Cos (2005). They found that some students dropped out of school because they found a job and could not combine schooling and working.

The above explanation cannot be used to explain why there are more dropouts in rural schools than urban ones as found in this study. The situation can be explained with the following reasons. (1) In the rural areas, there is high poverty rate among parents. This may have influenced their inability to meet the financial demands for their children schooling. This agrees with the findings of Sweeten (2004), Kaufman, et al (2001); Iceland (2003), and Schargel (2001) who isolated economic reason as one of the reasons for dropout. (2) Most of the parents in rural areas are illiterates who do not know the value of education. (3) Most of the pupils in rural schools have very poor primary and junior secondary school background. This most often result in high failure rate among the students and eventual dropout from school. This position agrees with the findings of Mohsin, et al (2004). They found poor primary education as one of the major causes of dropout in Punjab, Pakistan. (4) Most students are used in farming activities, which is the dominant occupation of parents in the rural areas. (5) Most females in the rural area are given out in marriage very early. This is because most parents in rural areas are very reluctant in sending their female children to school. (6) The very poor state of all resources for teaching and learning in rural schools does not encourage the youths to have faith in education and remain in school.

The findings of this study generally portray one obvious fact which is that the incidence of dropout from schools is very high in Nigeria. This therefore tends to suggest that the development may be responsible for the eruption of so many social vices in the Nigerian nation. Such social problems include: very high level of unemployment; high level of youths restiveness across the country; very high level of robbery, assassinating and kidnapping; high level of prostitution both within and outside the country; and very high incidence of child abuses leading to teenage pregnancy and the problems associated with it.

The problem of unemployment as found in Nigeria is not entirely due to lack of spaces in the existing industries, ministries and parastatals. To some extent, the issue can be explained through the angle that most of the unemployed youths are not employable because of lack of appropriate skills required for the existing jobs. Recent advances in 
technology have fueled the demand for a highly skilled labour force which the dropouts do not have. This makes them more likely to be unemployed than the high school graduates.

Again the high level of youth restiveness may also be linked to the very high incidence of dropout from school. This is hinged on the fact that the members of various militant groups across the country are made up of youths of ages between 15-20 who dropped out of school. In the south-south part of Nigeria, there are different militant youth groups used by politicians to advocate for resource control in Niger-Delta which is very rich in oil. In the Northern part of Nigeria, there are the "Alamanjeries" who are used by politicians in the North to protest political issues and policies . They kill, mame and burn down properties without any remorse of conscience. The "Alamanjeries are children under Islamic scholars to acquire Islamic education. Most if not all of the "Alamanjeries" do not have access to western education. All the militant groups whether in the North or South perpetuate different evil out of ignorance because of not having the right education which would have moderated their behaviours.

There is also very high level of robbery, assassination and kidnapping associated with youths most of whom are school dropouts. In fact, Nigeria is today most insecure because of criminal youths activities. This insinuation agrees with the position held by both the electronic and print media from a survey that over $85 \%$ of criminal activities perpetuated in Nigeria are done by youths who dropped out of school. This again agrees with the position held by the National Center for Education Statistics (1998) on the consequences of dropping out of school that school dropouts make up a disproportionate percentage of the nation's prisons and death roll imamates.

The high rate of prostitution in the country practiced both within and outside Nigeria can also be linked to school dropout because of the category of females involved. A reasonable percentage of females who dropped out of school engage in prostitution not for the sake of sexual satisfaction but because of financial difficulties since they are not employable.

The high incidence of dropout in Nigeria may also be linked to the high level of child abuses prevalent throughout the country. The abuses range from children being made to hawk when their mates are in school through going to the farm, to sexual abuses. The sexual abuses result in teenage pregnancies, early parenthood, and single parents who are unable to take care of themselves and their children. Stressing the inability of dropouts to take care of themselves, Bridgeland et al (2006) noted that students who drop out of school are often unable to support themselves and are twice as likely as high school graduates to slip into poverty from one year to the next.

All the developments as discussed above, which may be linked to the high incidence of dropout in Nigerian schools, tend to suggest that the high level of illiteracy as found among the youths in Northern Nigeria, Middle Belt, South Eastern Nigeria and South- South part of Nigeria except Edo and Delta states are products of school dropout. It was for the purpose of addressing the problems of school dropout and the high level of illiteracy found among youths that the Federal Government of Nigeria introduced the nine year compulsory Universal Basic Education (UBE) for all youths in Nigeria.

While the results of this study as shown in the tables above may seem to be natural, common sense result, it is significant that the data now show that dropout is seriously influenced by sex, school type and environment. The pattern of dropout established with the data collected provides an opening on the appropriate time to act to reduce the incidence of dropout in Nigerian schools.

\section{Conclusion}

Generally, the pattern of dropout from school in senior secondary schools in Delta State shows a picture with high percentage of dropouts in SSI and a decline of dropouts in SSII. The pattern of dropout from school as found in this study is influenced by school types (Single Sex vs Mixed, and Public vs Private), sex of students (male and female) and school environment (Urban vs Rural). It is concluded that the single most important factor which influence students pattern of dropout from school in the sex of the students. This is closely followed by the environment of the school.

The multiple factors associated with dropout rates and the varied nature of these factors from one community/ country to another, suggest that no single type of intervention strategy can end dropout problem in any nation. It therefore follows that whatever strategies that are recommended, must be seen to suit the characteristics of the environment for them to make a significant impart.

\section{References}

Ajaja, O.P., Kpangban, E., \& Onwuegbu, O.C. (2007). Motivation effect on test scores of senior secondary science student's. Studies on home and Community Science, 1(1); 57-64

Balfanz, R., \& Nettle, L. (2004). Locating the dropout crisis: Which high schools produce the nation's dropouts? 
[Online] Available: http://www.csos.jhu.edu/fdhs/rsch/locatingdropouts.pdf. (15 Feb, 2009)

Borich, G.D. (2004). Effective teaching methods: Fifth education. New Jersey: Pearson Merrill Prentice Hall.

Bridgeland, J.M, Dilulio, J.J. \& Morison, K.B. (2006). The silent epidemic. New York: Civic Enterprises, LLC.

De Cos, P.L. (2005). High school dropouts, enrollment, and graduation rates in California. California: California Research Bureau, California State Library.

Fafunwa, A.B. (1983). Dropout in the Nigeria education system. In S.A. Adesina, \& Ajayi, E. (Eds) Nigeria Education Trends and Issues. Ile Ife: University of Ife Press, Nig. Ltd.

Freudenberg, N., \& Ruglls, J. (2007). Reframing school dropout as a public health issue. [Online] Available: http//www.cdc.gov/pcd/issues/oct/07 (July 6, 2010)

Green, J.P., \& Marcus, W. (2005). Public school graduation and college readiness rates: 1991-2002. New York: Manhattan Institute for Policy Research.

Green, J.P., \& Marcus, W. (2005). Public school graduation rates in the United States. New York: Manhattan Institute for Policy Research.

Iceland, J. (2003). Dynamics of economic well-being: Poverty 1996-1999. Washington DC: U.S Census Bureau.

Johnson, B., \& Christensen, R. (2000). Educational research Boston: Allyn and Bacon.

Kaufman, P., Denise, B., \& Jeffrey, O. (1992). Characteristics of at-risk students in NELS: 88. Washington, DC: National Centre for Education Statistics.

Kaufman, P., Martha, N AR., \& Christopher, C. (2001). Dropout rates in the United States: 2000. Washington, DC: National center for Education Statistics.

Mohsin, A.O., Aslam, M., \& Bashir, F. (2004) Causes of dropouts at the secondary level in the Barani areas of the Punjab (a case study of Rawalpindi district). Journal of Applied Sciences, 4 (1); 155-158. http://dx.doi.org/10.3923/jas.2004.155.158.

National Centre for Education Statistics. (1998). Dropout rates in the United States. [Online] Available: http://www.ed.gov/stats.htm. (February 17, 2009)

Oghuvbu, E.P. (2008). The perceived home and school factors responsible for dropout in primary schools and its impact on National development. Ekpoma Journal of Behavioural Sciences, 1, 234-235.

Okoye, V.V.I. (1991). Investigation into the causes of male dropouts in selected secondary schools in Anambra State. Unpublished M.Ed Thesis of Anambra State University of Technology.

Schargel, F.P., \& Smink, J. (2001). Strategies to help solve our dropout problem. New York: Eye on Education.

Swanson, C.B. (2004). Who graduates? Who doesn't? A Statistical portrait of public of high school graduation. Washington, DC: The Urban Institute.

Sweeten, G.A. (2004). School dropout and subsequent offending distinguishing selection from causation. [Online] Available: http://www.lib.umd.edu/drum/bitsreani/1903/191/1 /dissertation.pdf. (February 15, 2009)

Vermont Agency of Human Services (1999). What works: keeping youth in school in your community. [Online] Available: http//www. ahs. state.vtus. (February 18, 2009)

Wiseman, DC. (1999). Research strategies for education. New York: Wadsworth publishing company. 
Table 1. Analysis of Dropout Pattern in Sampled Schools

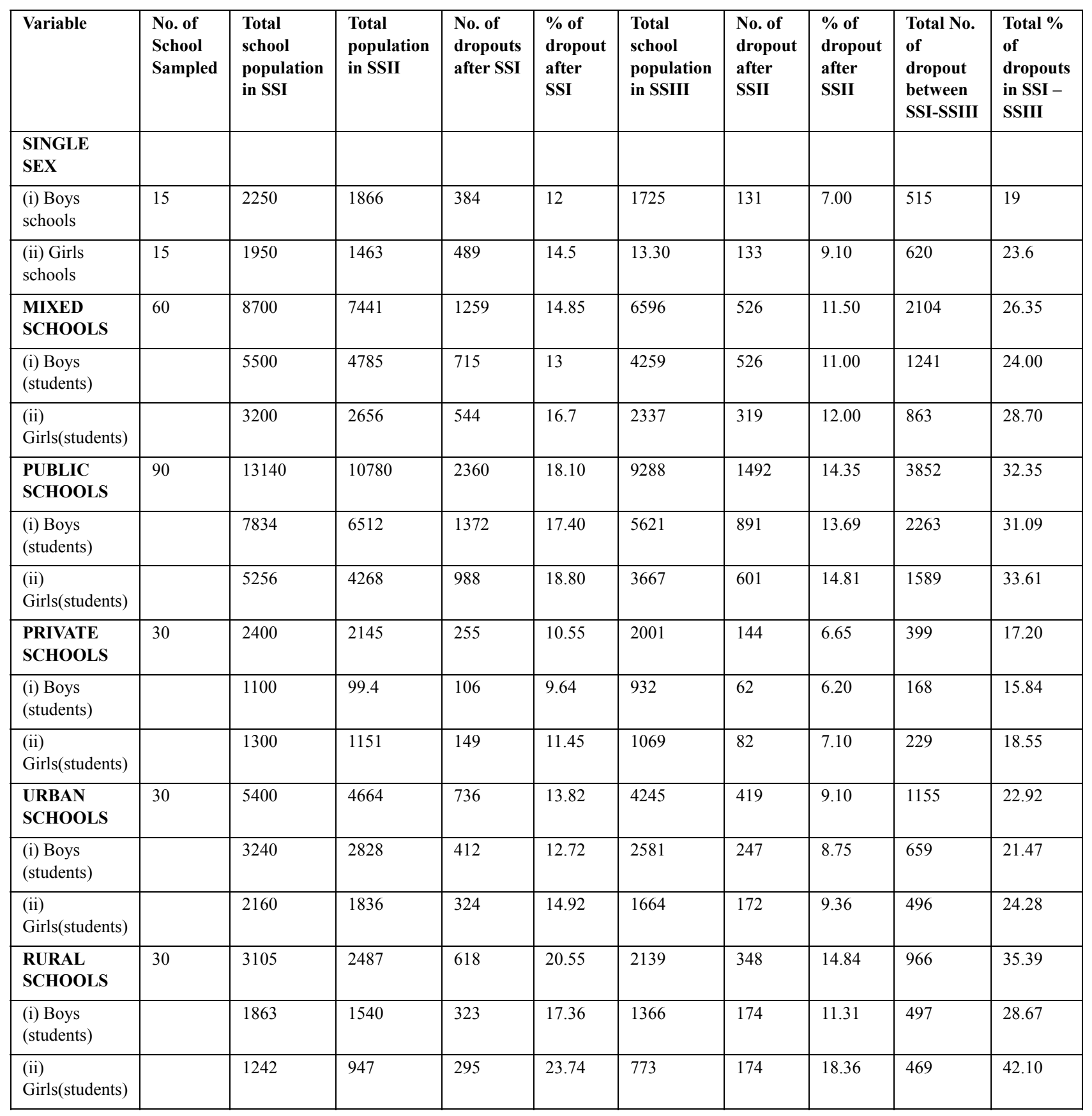


Table 2. T-Test Summary Table Comparing Percentage of Dropout in Male and Female Single Sex Schools

\begin{tabular}{|l|l|l|l|l|l|l|}
\hline Type of school & $\mathrm{N}$ & Mean & SD & df & $\mathrm{t}$ & $\mathrm{p}$ \\
\hline Boys school & 15 & 19.00 & 1.00 & 28 & 12.23 & 0.05 \\
\hline Girls & 15 & 23.27 & 0.91 & & & \\
\hline Mean differences & & 4.27 & & & & \\
\hline
\end{tabular}

Table 3. T-test summary table comparing percentage of dropouts in mixed and single sex schools

\begin{tabular}{|l|l|l|l|l|l|l|}
\hline Type of school & N & Mean & SD & df & t & $\mathrm{p}$ \\
\hline Single sex & 30 & 21.3 & 1.56 & 28 & 10.13 & 0.05 \\
\hline Mixed school & 30 & 26.1 & 1.74 & & & \\
\hline Mean differences & & 4.8 & & & & \\
\hline
\end{tabular}

Table 4. T-test summary table comparing percentage of dropouts in urban and rural schools

\begin{tabular}{|l|l|l|l|l|l|l|}
\hline Type of school & N & Mean & SD & df & t & p \\
\hline Single sex & 30 & 21.80 & 1.56 & 58 & 27.68 & 0.05 \\
\hline Mixed school & 30 & 34.40 & 1.74 & & & \\
\hline Mean differences & & 12.68 & & & & \\
\hline
\end{tabular}

